\title{
J. J. Grandville y la semiósis corporizada del gesto estético. A propósito de las caricaturas que integran la revista Ciencias Sociales y Educación n. ${ }^{0} 1{ }^{*}$
}

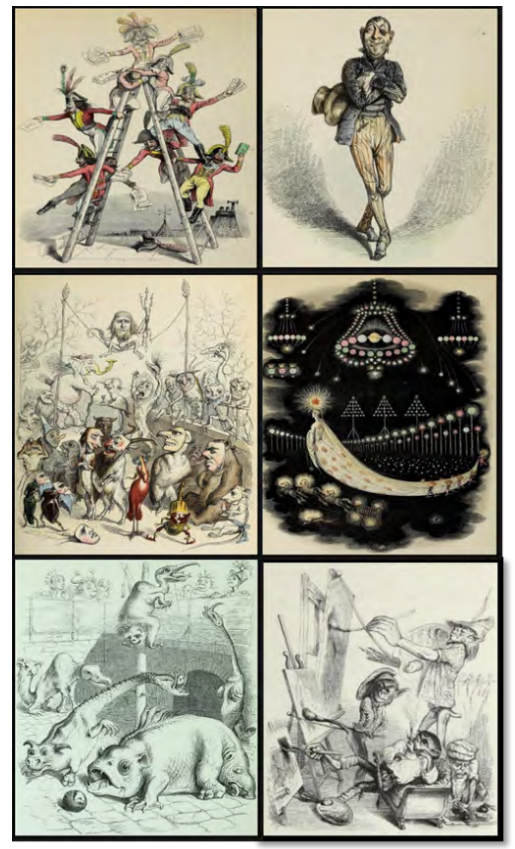

Selección de imágenes que integran este número de la revista n. ${ }^{\circ} 18$

Fuente: Grandville (1844, pp. 279, 8, 42, 95, 113 y 77).

Hilderman Cardona-Rodas

Facultad de Ciencias Sociales y Humanas Universidad de Medellín, Medellín, Colombia hcardona@udem.edu.co https://orcid.org/0000-0002-6778-2102

Cómo citar: Cardona Rodas, H. (2020). J. J. Grandville y la semiosis corporizada del gesto estético.

A propósito de las caricaturas que integran la revista Ciencias Sociales y Educación no. 18. Ciencias Sociales y Educación, 9(18), 323-330. https://doi.org/10.22395/csye.v9n18a18

Recibido: 15 de agosto de 2020.

Aprobado: 15 de septiembre de 2020. 
Una litografía publicada en 1840 por Émile Lassalle (1813-1871) muestra de perfil a J. J. Grandville; he aquí una persona de cuarenta años de ojos grandes, como mirando a otro mundo, con traje de etiqueta de la época, barba y cabello arremolinado. J. J. Grandville, caricaturista francés, cuyo verdadero nombre era Jean Ignace Isidore Gérard, nació en Nancy en 1803 y murió en el asilo de alienados de la comuna Vanves de la Île-de-France en 1847; fue uno de los ojos satíricos de la comedia de la imagen en la primera mitad del siglo XIX, alguien que supo expresar la golosina caníbal (Bataille, 2008, pp. 37-39) de la potencia de la mirada que toca y se apodera de una otredad, lo cual quedó expresado en la pesadilla dibujada por Grandville poco antes de su muerte, consistente en un criminal que sueña el asesinato que cometió: la victima suplica por su vida mientras el asesino hace correr la sangre en un acto de sacrificio sádico, ya que el arma irá transmutándose en ojo que persigue al criminal en un eterno devorar de la mirada, siendo muchos ojos más los que se multiplican ante la sangre humana derramada. Esta pesadilla tiene su presencia en la poética de Víctor Hugo (1805-1885), recordado por Bataille, cuando el novelista francés se obsesiona por el ojo de la conciencia ante la sangre que sigue fluyendo. "¿Por qué El Ojo de la Policía, semejante al ojo de la justicia humana en la pesadilla de Grandville, después de todo no es más que la expresión de una ciega sed de sangre?" (Bataille, 2008, p. 39).

El sueño del criminal evoca a la aversión y horror que produce la posibilidad de ingerir los ojos de los animales, lo cual propicia que hayan sido excluidos de los rituales de comensalidad de la modernidad occidental. En este ritual de la mirada que come en el banquete de los sentidos, se pone en juego la posibilidad de una temida metamorfosis caníbal. Por tanto, la mirada humana, que también opera como "ojo de la conciencia", expresa allí "un rasgo extremadamente elevado de horror" frente al encuentro con esa especie golosina caníbal que constituyen los ojos de estos otros seres convertidos en alimentos; ¿sería acaso los mil ojos de la multitud atraída por el espectáculo del suplicio inminente?, se pregunta Grandville en los ojos cálidos de Georges Bataille. Así, la afirmación de Charles Baudelaire (1821-1867), según la cual el caricaturista francés era un espíritu enfermizamente literario (Baudelaire, 2001, p. 157), se da en toda su revelación háptica (ojo que toca y tacto que ve) al retratarse como experiencia estética propia de una de las facetas de la historia del arte.

Grandville es el autor de los siguientes libros ilustrados con sus litografías satíricas: Les Plaisirs de toutdge, La Sibylle des salons, Les Métamorphoses du jour, La Vie privée et publique des animaux, Les Cent Proverbes, Un Autre Monde y Les Fleurs animées. En cada una de estas obras, le da forma a una pregunta por la corporalidad de la condición humana en las expresiones de sus emociones. Así, 
en su obra las huellas de la rostridad se hacen visibles en un régimen satírico que mezcla cuerpo humano y rostros animales.

El rostro solo se produce cuando la cabeza deja de formar parte del cuerpo, cuando deja de estar codificado por el cuerpo, cuando deja de tener un código corporal polívoco multidimensional -cuando el cuerpo, incluida la cabeza, está descodificado y debe ser sobrecodificado por algo que llamaremos Rostro. (Deleuze y Guattari, 2004, p. 176)

En los dibujos de Grandville la desterritorialización —mencionada por Deleuze y Guattari-se presenta en la transmutación zoofitoantropológica que se opera en sus figuras, siendo perceptible, con ello, el vínculo con la tradición de la fisiognomía proveniente de la antigua Grecia, que enlaza las palabras Physis (Naturaleza) y Gnomon (Interprete, Maestro o Juez). Esta tradición parte de una lectura de las apariencias físicas de una persona, del latín persōna (máscara del actor, personaje teatral), escenificadas en el rostro. Para el siglo XIX, la fisiognomía tendrá su campo de aparición en la frenología, obsesionada por la medición de los cráneos en las especulaciones de Franz Joseph Gall (17581828), y las artes plásticas que intentan captar las superficies del temperamento humano, asociándolas a una animalidad encarnada en el rostro. Esta inquietud semiótica se encuentra en Aristóteles (384-322 a. C.), pasando por Giovanni Battista della Porta (1535-1615), Charles Le Brun (1619-1690), Johann Caspar Lavater (1741-1801) y David Pierre Giottino Humbert de Superville (1770-1849)1. En un pasaje de la Revue de Paris de junio de 1836, esta analítica del rostro es retratada de la siguiente forma:

Las fisiognomías son tan variadas como los trajes: aquí, una cabeza majestuosa, como las figuras de Murillo; allá, un rostro vicioso de gruesas cejas, que revela una energía de criminal decidido [...] Acullá una cabeza de árabe se dibuja sobre un cuerpo de chiquillo. He aquí unas facciones femeninas y suaves: son unos cómplices; contémplese esas caras brillantes de libertinaje: son los preceptores. (Cita Foucault, 2009, p. 300)

La expresión de las emociones que se manifiesta en la obra de Grandville, de las cuales la revista Ciencias Sociales y Educación, en su número 18, ha retomado algunas, pone en juego una semiósis corporizada de las máscaras de lo humano, lo que hoy se denomina hexis corporal, entendida como disposición, posesión o estado activo desde la perspectiva aristotélica, la cual es estudiada por Pierre Bourdieu (2011) desde el concepto de habitus, que entraña maneras de ser,

Para este orden de problemas relacionado con una semiótica del rostro y del cuerpo para hallar los rasgos psicológicos de las personas, ver Pseudo Aristóteles (2019); Delaporte (2007); Deleuze y Guattari (2004) y Magli (1992). En ese sentido, Claude Gueux (pequeña novela de Victor Hugo publicada en 1843, donde se critica la pena de muerte) llegará a firmar que: "palpad todos esos cráneos [...] cada uno de esos hombres caído por debajo de sí mismo hasta su tipo bestial [...]. He aquí el lince, he aquí el gato, he aquí el mono, he aquí el buitre, he aquí la hiena." (Cita Foucault, 2009, p. 300). 
aspecto externo, constitución o conformación física ${ }^{2}$. Así, plantear el problema de una hexis corporal permite disolver el dualismo antropontológico entre cuerpo y alma, subjetividad y objetividad o racionalidad y sensibilidad que fundamenta la tradición occidental, ya que toda experiencia corpórea es el punto de partida de la acción humana en un mundo cultural. La obra de J. J. Grandville refleja éste interés por revelar costumbres y hábitos en su asociación estética entre el ser humano con los demás animales.

Una semiósis corporizada en la interpretación fisiognómica del rostro presente en los dibujos de Grandville recuerda la narrativa de Honoré de Balzac (1799-1850), quienes fueron amigos. Balzac $(2014,2019)$ en su proyecto narrativo La Comédie humaine, integrada por 85 novelas y 9 textos entre ensayos y relatos, proyecta un retrato de la sociedad francesa desde la caída del Imperio Napoleónico (1815) al comienzo de la Monarquía de Julio (1830), buscando con ello comprender las especies sociales a la manera como la biología decimonónica analizó las especies zoológicas. Este proyecto vuelve a poner en escena, en el espacio literario, una inquietud por un desciframiento de los cuerpos en una rostridad del carácter. Grandville ilustró muchos de los relatos de Balzac, además de participar con él en Études de mœur contemporaines $(1840)^{3}$, o Los estudios morales contemporáneos, que dirigió Pierre-Jules Hetzel (1814-1886), como ilustrador de los textos de la obra. Hetzel escribió con Balzac Cuitas de amor de una gata inglesa / Cuitas de amor de una gata inglesa bajo el seudónimo P-J. Stahl, y será Grandville quien ilustre el texto a partir de su espíritu enfermizamente literario.

El 9 de septiembre de 1835 se impone la censura sobre la caricatura política en Francia; el retorno del rey francés en la Monarquía de Julio, significó la actualización del miedo ante la imagen que provoca malestar, ya que palpita por su poder de sátira sobre la hipocresía del mundo burgués. Así, los seis dibujos seleccionados del libro de Grandville Un Autre Monde (1844) para el presente número de la revista, teatralizan un momento de la historia de Francia, consistente en furia y sorpresa (portada), que continúa con una expectación sarcástica (primer interior), ante las máscaras de lo político (segundo interior),

Los conceptos hexis corporal y habitus de P. Bourdieu de nutren de las reflexiones de Marcel Mauss sobre las técnicas del cuerpo (Mauss, 1966). Según Mauss: "El conjunto de los hábitos del cuerpo es una técnica que se enseña y cuya evolución no ha terminado. La técnica de la natación se perfecciona cada día" (Mauss, 1989, p. 30).

3 He aquí la publicación de las piezas gráficas de Grandville publicadas en 1841 con el título Scénes de la vie priveé et publique des animaux (Vida privada y pública de los animales I y II, 1984), las cuales integran la obra que dirigió P- J. Stahl, Études de mœur contemporaines. Esta vida privada y pública de los animales es una colección de cuentos cortos satíricos que aparecieron por entregas entre 1840 y 1842 en las revistas Le caticuture y Le charivari, donde se publicaban sátiras de las costumbres políticas de la época, lo cual le significó el cierre de la primera revista con la censura de la caricatura política en Francia el 9 de septiembre de 1835, en el contexto del retorno de la monarquía (1830-1848) con el reinado de Luis Felipe I (1773-1850). 
que se proyectan en una desilusión que enceguece a todos (tercer interior), ante un drama cómico (cuarto interior) que reproduce la fábula de lo político (quinto interior). En los años de censura a la caricatura política, Grandville se dedicó a ilustrar novelas como Don Quijote de la Mancha, Los viajes de Gulliver y Robinson Crusoe, además de las fábulas de Jean de La Fontaine. Los dibujos que dedicó al fabulista francés son expresión de aquella semiosis corporizada de su gesto estético, pues Grandville hace de la imagen un dispositivo crítico para la comprensión de la condición cómica de lo humano. Un estremecimiento de procedimientos ópticos para generar malestar:

Cuando entro en la obra de Grandville, siento un cierto malestar, como en el apartamento en el que el desorden estuviera sistemáticamente organizado, en el que estrafalarias cornisas se apoyan sobre el suelo, en el que los cuadros aparecieran deformados por procedimientos ópticos, en el que los objetos se hirieran oblicuamente por los ángulos, o los muebles tuvieran las patas por el aire, y en el que los cajones entraran en lugar de salir. (Baudelaire, 2001, p. 158)

Este patas arriba de las cosas sensibles en la obra del caricaturista francés, flamea en la estética surrealista del siglo XX, que pone en juego realidades alucinadas del mundo de los sueños y del subconsciente por la mediación de formas abstractas y figuraciones simbólicas que enfatizan en fragmentos anatómicos, elementos extravagantes, máquinas fantásticas, metamorfosis, autómatas, presencia del caos en espasmos vacíos y fusiones entre desnudos y maquinarias. Lo estrafalario como procedimiento estético deja ver un tejido onírico que hace estremecer lo que ha sido designado como real, puesto que a esa realidad se la parodia desde un mundo al revés que Grandville fraguó en su obra.

Para terminar esta reseña, uno de los dibujos que realizó Grandville para las fábulas de Jean de La Fontaine fusiona imagen y palabra en una semiosis corporizada que satiriza las relaciones parasitarias humanas. Le rat de ville et le rat des champs (La rata de ciudad y la rata de campo) relata la invitación de una rata de ciudad a una rata de campo para compartir un banquete sobre un tapiz de Turquía. Ambas roen y mordisquean las sobras de manjares. "Esas sobras no son más que restos, residuos o migajas: el agasajo, el festín, no es más que un banquete después del banquete, el sucio abandono de la mesa que quedó sin levantar." (Serres, 2015, p. 49) 4 . Un parásito invita a un semejante a comer en la casa de su hospedero para disfrutar una buena vida a costa de otro. El placer de las buenas viandas relaja a los dos comensales, pero un ruido súbito, que proviene de la puerta, las asusta. Es un mensaje que genera pánico ante la posible presencia de un tercer personaje de mediación parasitaria en el flujo de la comunicación. He aquí la fábula de La Fontaine y el dibujo de Grandville:

\footnotetext{
La primera edición en francés del libro de Michel Serres, publicada por Bernard Grasset en 1980, ofrece en su carátula el dibujo de Grandville sobre la fábula de La Fontaine, siendo la obertura de una reflexión sobre el ruido parásito que intercepta todo flujo en la comunicación.
} 
Autrefois le Rat de ville

Invita le Rat des champs,

D'une façon fort civile,

A des reliefs d'ortolans.

Sur un tapis de Turquie

Le couvert se trouva mis:

Je laisse à penser la vie

Que firent ces deux amis.

Le régal fut fort honnête,

Rien ne manquait au festin;

Mais quelqu'un troubla la fête,

Pendant qu'ils étaient en train.

A la porte de la salle

Ils entendirent du bruit;

Le Rat de ville détale,

Son camarade le suit.

Le bruit cesse, on se retire:

Rats en campagne aussitôt;

Et le Citadin de dire:

Achevons tout notre rôt.

C'est assez, dit le Rustique;

Demain vous viendrez chez moi.

Ce n'est pas que je me pique

De tous vos festins de roi;

Mais rien ne vient m'interrompre;

Je mange tout à loisir.

Adieu donc; fi du plaisir

Que la crainte peut corrompre! (La Fontaine, 1855, pp. 22-23) ${ }^{5}$

5 La versión en español de Bernardo María de Calzada, publicada en Madrid en 1787, tiene el gusto jocoso propio de finales del siglo XVIII: "Un Raton de la ciudad, / Á otro Raton campesino / Combido á comer muy fino, / Y de buena voluntad. / Púsose sobre un tapete / El cubierto: iqué alegría / Á los dos nos causaría / Tan amigable banquete! / La comida fue abundante: / No faltó nada en la fiesta; / Pero interrumpiose esta / En el más plácido instante. / Hacia la puerta cerrada / Del quarto, rumor se oyó: / El Raton civil huyó, / Y detrás su camarada. / Cesó el ruido: vuelven luego; / Y, azorado el ciudadano, / Dixo al campesino: hermano, / Comamos, y ten sosiego. / No, no; basta de mascar, / Replicó: en el campo espero. / Y no creas, que altanero / Te pretenda yo imitar. / Será el combite menor; pero comeremos sin sustos. / iMal hayan, amen, los gustos / Mezclados con el temor." (La Fontaine, 1787, pp. 22-23). 


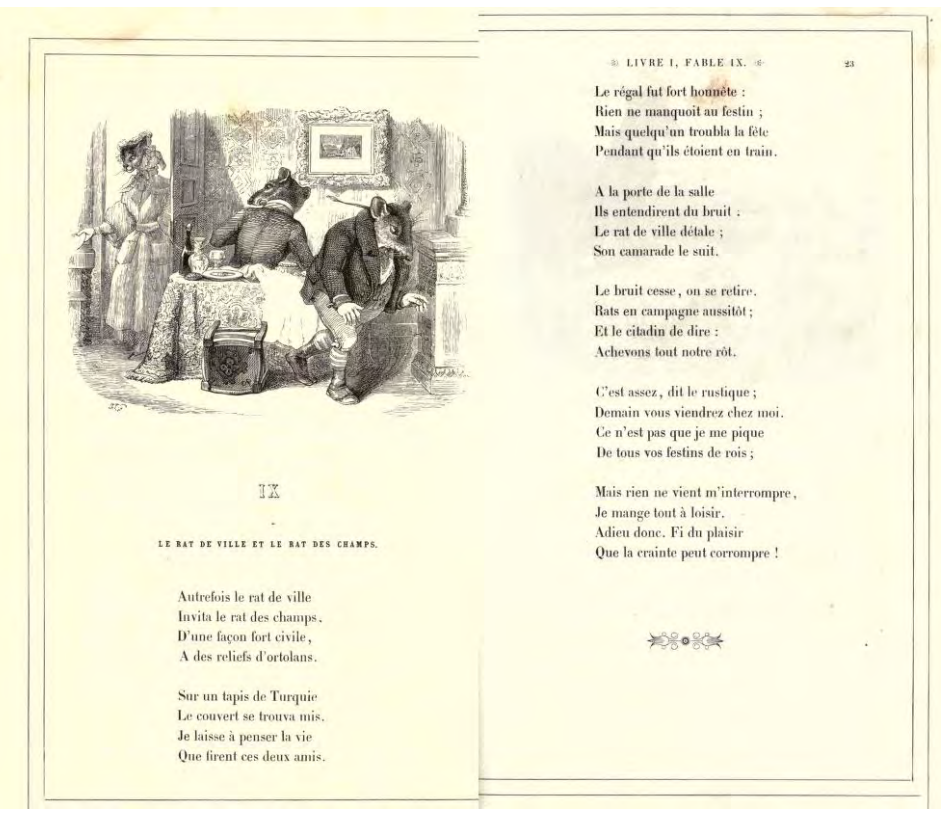

La rata de ciudad y la rata de campo, dibujo de J. J. Grandville de una fábula de La Fontaine.

Fuente: La Fontaine, 1855, p. 23

\section{Referencias}

Bataille, G. (2008). La conjugación sagrada. Ensayos 1929-1939. Adriana Hidalgo Editora.

Balzac, H. y Stahl, P. J. (2020). Cuitas de amor de una gata inglesa / Cuitas de amor de una gata inglesa. Alianza Editorial.

Balzac, H. (2014). La comedia humana (4 volúmenes). Hermida Editores S.L.

Baudelaire, C. (2001). Lo cómico y la caricatura. La balsa de la Medusa.

Bourdieu, P. (2011). Las estrategias de la reproducción social. Siglo veintiuno editores.

Delaporte, F. (2007). Anatomía de las pasiones. Ediciones Uninorte.

Deleuze, G. y Guattari, F. (2004). Mil Mesetas. Capitalismo y esquizofrenia. Pre-Textos.

Foucault, M. (2009). Vigilar y castigar. Nacimiento de la prisión. Siglo XXI Editores.

Grandville, J. J. (1844). Un Autre Monde. H. Fournier. https://archive.org/details/unautremondetran00gran

Grandville, J. J. (1841). Scénes de la vie priveé et publique des animaux. J. Hetzel et Paulin. https:// gallica.bnf.fr/ark:/12148/btv1b86002022/f7.item

Grandville, J. J. (1984). Vida privada y píblica de los animales I y II. Ediciones Generales Anaya. 
La Fontaine, J. de (1855). Fábulas morales escogidas de Juan de La Fontaine en verso castellano. Imprenta Real. http://cdigital.dgb.uanl.mx/la/1020025993_C/1020025993_T1/1020025993.PDF

La Fontaine, J. de (1855). Fables de La Fontaine. Illustrations par Grandville. Garnier Fréres. https:// archive.org/details/fablesdelfontain00lfonrich/page/n9/mode/2up

Magli, Patrizia (1992). El rostro y el alma. En Michel Feher, Ramona Naddaff y Nadia Tazi (eds.). Fragmentos para una historia del cuerpo humano, tomo 2 (pp. 87-127). Taurus.

Mauss, M. (1989). Manuel d'ethnographie. Payot. [Manual de etnografía. México: FCE, 2006].

Mauss, M. (1966). Les techniques du corps. En M. Mauss (ed.), Sociologie et Anthropologie (pp. 337356.). PUF.

Pseudo Aristóteles (2019). Fisiognómica. Mármara Ediciones.

Serres, M. (2015). El parásito. Co-Lectora. 